\title{
Isothermal Continuous Equal Channel Angular Pressing of Magnesium Alloy AZ31
}

\author{
CASEY F. DAVIS (1), ${ }^{1,3}$ ADAM J. GRIEBEL, ${ }^{2}$ and TERRY C. LOWE (1) ${ }^{1}$ \\ 1.-George S. Ansell Department of Metallurgical and Materials Engineering, Colorado School of \\ Mines, Golden, CO 80401, USA. 2.-Fort Wayne Metals, Fort Wayne, IN 46809, USA. \\ 3.—e-mail: davisc@exponent.com
}

\begin{abstract}
Magnesium (Mg) alloys are promising candidate materials for use in absorbable implants. For this purpose, they must possess a combination of properties needed for specific medical applications such as coronary stents or trauma fixation screws. The typically low strength, low ductility, and rapid biodegradation of many $\mathrm{Mg}$ alloys limit their suitability for medical use. However, these problems can be addressed by creating ultrafine-grain (UFG) variants of $\mathrm{Mg}$ alloys. For this purpose, an economical continuous equal channel angular pressing (ECAP-C) method was applied to produce UFG AZ31 Mg. An ultimate tensile strength of $333.5 \mathrm{MPa}$ with an elongation of $28 \%$ was achieved, and continuous coil-to-coil ECAP-C processing was demonstrated.
\end{abstract}

\section{BACKGROUND}

Magnesium ( $\mathrm{Mg}$ ) and magnesium alloys are of growing interest for multiple industries, including the medical industry, because of their high specific strength and ability to be harmlessly absorbed by the body. In the context of medical devices, metallic implants that predictably degrade and are absorbed over time are alluring for several reasons. Current orthopedic devices such as plates, screws, and nails will often require a secondary removal surgery, incurring additional risk of infection, patient discomfort, and cost. The extended presence of vascular devices (e.g., peripheral stents) will often lead to late-term restenosis. ${ }^{1}$ The propensity of $\mathrm{Mg}$ materials to corrode in aqueous environments, as well as Mg's status as an essential nutrient, makes it a primary candidate for absorbable metallic implants. Successful implementation of a Mg-based device requires managing the natural limitations of $\mathrm{Mg}$, namely, low strength, low ductility, and an excessively high corrosion rate. Thus, a growing body of research has been reporting methods to increase strength while maintaining or increasing ductility and reducing the corrosion rate. ${ }^{2-4}$

One method for achieving increased strength, ductility, and corrosion resistance is severe plastic deformation (SPD), a group of metalworking techniques involving a high level of shear deformation. Equal channel angular extrusion/pressing (ECAE/
ECAP), a method of SPD, has demonstrated the ability to improve the mechanical properties while changing the corrosion resistance of several $\mathrm{Mg}$ alloys. $^{3,5-7}$ Most results on ECAP of Mg show a decrease in strength with an increase in ductility. ${ }^{7-16}$ Additional results show minor changes in mechanical properties despite significant grain refinement, ${ }^{17}$ and a few reported increased strength and increased ductility. ${ }^{3,18-20}$ ECAP has also shown the ability to make Mg superplastic. ${ }^{8,10,12,14,21}$ Additionally, Kim et al. demonstrated ECAP processing of AZ31 affected fatigue life by increasing the propensity for crack initiation due to lower yield stress and yield anisotropy, but decreasing the rate of crack growth due to the refined grain structure. ${ }^{22}$ Finally, work by Wang et al. established that deformation processing via hot rolling or ECAP can reduce the corrosion rate of AZ31 when tested in Hank's solution (a solution that simulates body fluids). ${ }^{23}$ Mostaed et al. demonstrated that the electrochemical behavior measured by the free corrosion potential is unchanged after processing, but the weight loss rate is significantly reduced after ECAP. ${ }^{7}$ The type of corrosion was also changed from pitting/localized corrosion to uniform corrosion. This was attributed to the refined second phase present after processing.

While ECAP offers numerous material property advantages over a wide range of materials, the traditional ECAP process is not well suited to 
commercialization because of the associated short piece length. For ECAP to be commercially viable, it must allow for continuous or semi-continuous processing of workpieces and allow for integration into subsequent manufacturing processes. The most successful continuous process to date is continuous equal channel angular pressing (ECAP-C). Studies of ECAP-C of aluminum have shown similar grain refinement and mechanical properties as achieved by conventional ECAP ${ }^{24}$ but currently there is no reported research on the microstructures and properties achieved by ECAP-C of Mg alloys.

ECAP-C is similar to conventional ECAP, but there are four key differences between the two processes. First, in ECAP-C there is only minimal backpressure during shearing in the zone in which the metal flow undergoes a change in direction. Low backpressure narrows the shear zone at the entrance/exit channel intersection, as reported in experiments and numerical analyses by Lapovok et al. ${ }^{25}$ It also reduces the beneficial effects of hydrostatic pressure in mitigating the formation of voids or cracks, especially in hard-to-deform alloys such as Mg. Consequently, strategies to enhance grain refinement by reducing the processing temperature become challenging. Second, in ECAP-C there is a release of the confining pressure within a short time (seconds) after the material experiences intense shear. This is accompanied by elastic expansion and backflow/relaxation of dislocations. Third, ECAP-C offers the advantage of rapid cooling (or quenching) within a short time (seconds) after the material experiences intense shear. This provides some ability to control thermally activated processes such as recrystallization, grain growth, nucleation of new phases, and precipitation immediately following the intense shearing. Fourth, the force to feed ECAP-C billets through the shearing zone arises from friction with the die, not the axially applied pressure of conventional ECAP. This is advantageous in that only one of the four walls of the entrance channel resists flow of the billet through the tooling. Furthermore, while ECAP-C can be performed with cylindrical billets, our implementation of ECAP-C relies on using rectangular billet cross sections, which reinforces the planarity of intense shear, resulting in improved homogeneity.

The focus of this research is to determine whether ECAP-C can be applied to a $\mathrm{Mg}$ alloy and, if successful, establish the range of feed rates, temperatures, and billet rotation schemes best suited for commercially viable continuous ECAP processing to achieve desirable microstructures and mechanical properties.

\section{MATERIALS AND EQUIPMENT}

An AZ31-B extruded magnesium rod (hereafter labeled AZ31) with a starting diameter of $12.5 \mathrm{~mm}$ supplied by MetalMart International, Inc., was used in this research. The starting microstructure had coarse grains elongated in the extrusion direction (ED). The AZ31 rod was sectioned into lengths between $300-450 \mathrm{~mm}$ for ECAP-C processing. A third-generation ECAP-C machine (Model Gamma) was used with the exit channel set to output rods with an $11 \mathrm{~mm} \times 11 \mathrm{~mm}$ cross section. All processing was completed using a $120^{\circ}$ die channel angle, producing an equivalent strain of 0.67 per pass, which allowed for lower processing temperatures while also not requiring backpressure to prevent cracking. ${ }^{12}$ Billets were preheated for $20 \mathrm{~min}$ in an atmospheric tube furnace (Lindberg Model 5567 Furnace with a Lindberg Model 58475-P-B-93 Furnace Controller). The selection and evaluation of processing conditions and parameters are described in detail in subsequent sections since they are the focus of this research.

After ECAP-C processing, samples for microstructural characterization were extracted from the AZ31 billets. The sectioning was performed using an Allied TechCut 4 Low-Speed Saw with Allied Cutting Fluid. The saw was set to a speed of $300 \mathrm{rpm}$ with a weight of $300 \mathrm{~g}$ over the blade. Samples for microscopy were prepared by argon ion milling. The surface to be milled was ground using 1200 grit $\mathrm{SiC}$ paper to ensure a flat edge and removal of cutting-induced damage. After grinding, the samples were milled with a JEOL IB0910CP Cross-Section Polisher with an ion accelerating voltage of $5 \mathrm{kV}$ and argon flow rate of 4.04.5 (no standard units) for a total of $12 \mathrm{~h}$. A JEOL JSM-7000F field emission scanning electron microscope (FESEM) equipped with secondary and backscatter imaging, an EDAX Octane Pro SDD for energy-dispersive spectroscopy of x-rays (EDS), and an EDAX Hikari Pro 600pps Detector for electron backscatter diffraction (EBSD) were used to study the microstructural evolution in AZ31 created by ECAP-C processing. For billets processed to have the smallest grain sizes, it was necessary to conduct transmission Kikuchi diffraction (TKD) using 80-nm-thick foils prepared by gallium ion milling with a FEI Helios Dual Beam Nanolab 700i scanning electron microscope.

Tensile tests were conducted using samples machined to the ASTM E606 standard with a 10.2$\mathrm{mm}$ gauge length and 3:1 reduction in diameter from the grips to the gauge section radius. The E606 standard was selected over the ASTM E8 standard because previous mechanical tests showed the sensitivity of nanostructured material to stress concentrators present in ASTM E8 samples. Triplicates of each sample were tested to determine repeatability. The tensile tests were conducted using an MTS TestWorks software system controlling a screwdriven InstruMet load frame (serial no. 505318) with a 20,000-lb load cell (serial no. 104383). All tests were completed with a cross-head speed of $9.5 \times 10^{-3} \mathrm{~mm} / \mathrm{s}$, resulting in an initial strain rate 
of $9.3 \times 10^{-4} \mathrm{~s}^{-1}$. Strain measurements were made using an Aramis digital image correlation (DIC) system. All mechanical testing was conducted at room temperature.

\section{ECAP-C PROCESS TRIALS}

ECAP-C processing trials were performed to determine the limiting temperatures and linear feed rates achievable for the AZ31 Mg alloy. Low billet feed rates have been used by other researchers conducting ECAP to allow deformation by both slip and grain boundary sliding. ${ }^{26}$ For our initial study, the linear feed rate was set to the lowest feed rate possible for the Gamma ECAP-C machine, $0.2 \mathrm{~mm}$ / s. Trials were conducted at progressively lower temperatures in 50-K decrements in temperature, starting at $673 \mathrm{~K}$ until the material exhibited fracture at $373 \mathrm{~K}$.

These trials established that the range of processing temperatures for successful ECAP-C was between $423 \mathrm{~K}$ and $523 \mathrm{~K}$. Figure $1 \mathrm{a}$ shows an ECAP-C billet processed at $473 \mathrm{~K}$, and Fig. $1 \mathrm{~b}$ shows shear cracking during processing at $373 \mathrm{~K}$. The lowest temperature for successful ECAP-C was $423 \mathrm{~K}$ for the as-received ( $\mathrm{AR}$ ) coarse-grain $\mathrm{Mg}$.

This result agrees with published literature, which shows that localized shear bands form at temperatures $<473 \mathrm{~K}$. ${ }^{26}$ The occurrence of strain localization depends on the work-hardening properties and the strain-rate sensitivity of the material. These properties vary with grain size, with finer grains resulting in enhanced strain rate sensitivity. $^{27-29}$ Therefore, material with a finer starting grain size can be processed at lower starting temperatures.
Since strain localization depends on the strain rate, the linear billet feed rate was also assessed in the screening trials. As shown in Eq. 1, the amount of strain per pass is a function of the channel intersection angle $\Phi$ :

$$
\varepsilon=\frac{1}{\sqrt{3}}\left[2 \cot \left(\frac{\Phi}{2}\right)\right]
$$

Given a linear feed rate, $F$, and the width of the shear zone, $d$, the strain rate can be calculated as:

$$
\dot{\varepsilon}=\frac{F}{d}
$$

Equation 3 is obtained by substituting Eq. 1 into Eq. 2, which shows the strain rate is a function of $\Phi$, $F$, and $d$.

$$
\dot{\varepsilon}=\frac{F}{d \sqrt{3}}\left[2 \cot \left(\frac{\Phi}{2}\right)\right]
$$

It is difficult to measure an exact value for $d$. However, modeling shows $d$ can be as large as $5 \mathrm{~mm}$ when backpressure is applied and $2 \mathrm{~mm}$ for AZ31 with no backpressure. ${ }^{25}$

The last series of pre-screening trials was run to determine the degree of adiabatic heating during processing. The ECAP-C machine tooling was heated to $473 \mathrm{~K}$ with feed rates of $0.2 \mathrm{~mm} / \mathrm{s}, 0.5$ $\mathrm{mm} / \mathrm{s}, 1.0 \mathrm{~mm} / \mathrm{s}, 5.0 \mathrm{~mm} / \mathrm{s}$, and $10.0 \mathrm{~mm} / \mathrm{s}$ corresponding to effective strain rates between $0.033 \mathrm{~s}^{-1}$ and $3.3 \mathrm{~s}^{-1}$, assuming a shear zone width of $2 \mathrm{~mm}$. This range of conditions resulted in successful, controllable, and repeatable processing. At feed rates of $10 \mathrm{~mm} / \mathrm{s}$ and above, significant adiabatic heating occurred, so a maximum linear feed rate of $8 \mathrm{~mm} / \mathrm{s}$ was used in the next study: examining the
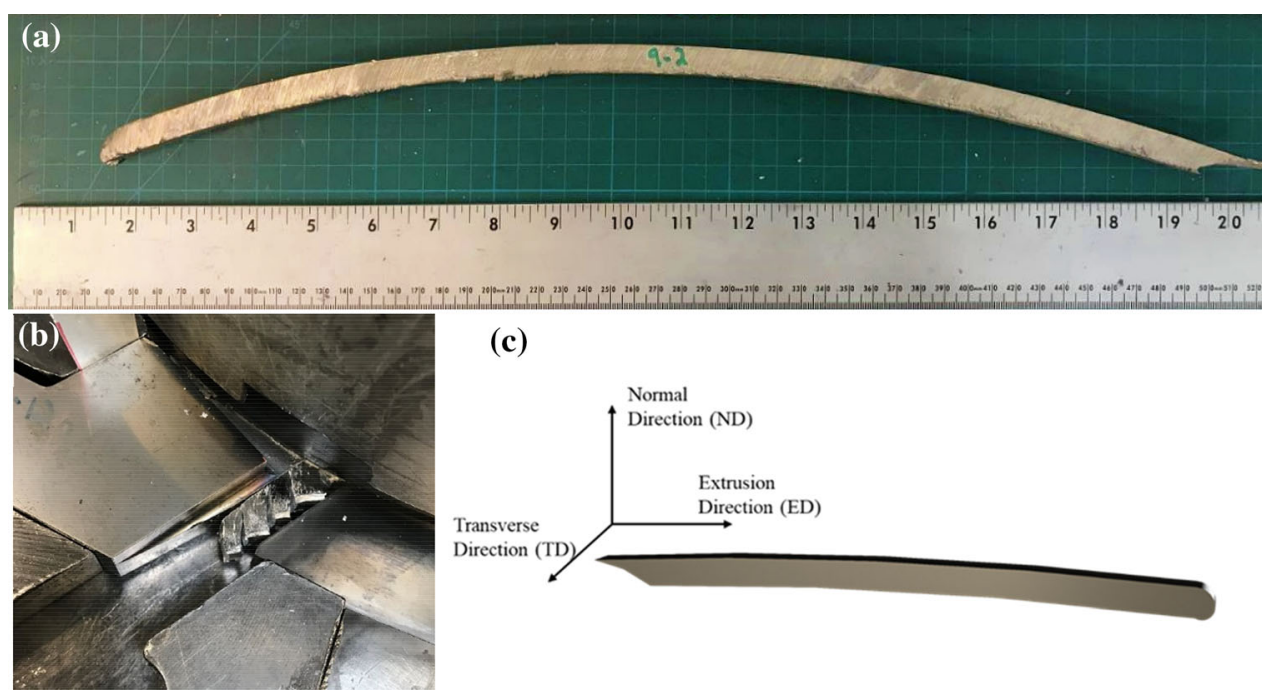

(c)

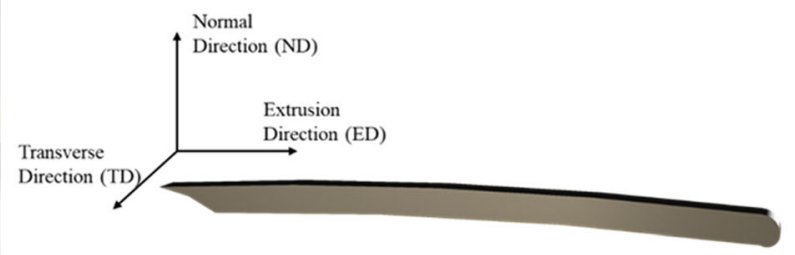

Fig. 1. AZ31 Mg processed using the Gamma ECAP-C machine at (a) $473 \mathrm{~K}$ and (b) exhibiting shear cracking in the exit channel because of processing at $373 \mathrm{~K}$ with no backpressure applied. (c) Reference axes for the billet extrusion direction (ED), transverse direction (TD), and normal direction (ND). 
effects of temperature, strain rate, and inter-pass rotation on the microstructure and tensile properties.

\section{RESULTS: MICROSTRUCTURES}

Based on the results of the screening trials, microstructures and mechanical properties were studied for AZ31 subject to ECAP-C at three temperatures ( $423 \mathrm{~K}, 473 \mathrm{~K}$, and $523 \mathrm{~K}$ ), three feed rates $(1 \mathrm{~mm} / \mathrm{s}, 3 \mathrm{~mm} / \mathrm{s}, 8 \mathrm{~mm} / \mathrm{s})$, and three levels of effective strain (1.34, 2.68, and 5.36, corresponding to 2-pass, 4-pass, and 8-pass ECAP-C, respectively).

Electron backscatter diffraction (EBSD) results in Figs. 2, 3, 4, and 5 show the influence of all processing parameters on the resulting microstructures after isothermal ECAP-C passes. In Fig. 2, the as-received (AR) grain structure for longitudinally sectioned billets is contrasted with the grain size, shape, and major axis orientation after two passes of ECAP-C at 423, 473, and $523 \mathrm{~K}$. Grains are colored to show the aspect ratio of the minor to major axes of ellipses fit to each grain. Equiaxed grains have an aspect ratio of 1 and are colored red, while elongated grains have aspect ratios closer to 0 and are colored green or blue. The AR AZ31 had a bimodal grain size distribution with the finer, equiaxed grains having an average diameter of 20 $\mu \mathrm{m}$. The coarse grains were in the range of $200-300$ $\mu \mathrm{m}$ in the extrusion direction and $100 \mu \mathrm{m}$ in the radial direction. The degree of grain shape anisotropy is greatest in the AR sample, as shown by the prominence of blue- and green-shaded grains. After ECAP-C, the average grain sizes were reduced to between $0.8 \mu \mathrm{m}$ and $3.3 \mu \mathrm{m}$, correlating with the shift of the apparent area-based median grain size in Fig. 3a. The average grain size is smallest at the lowest ECAP-C temperature of $423 \mathrm{~K}$ and increases systematically with increasing temperature. For all temperatures, the bimodality of the grain size distribution is shown in Fig. 2, with larger multimicron size grains surrounded by much smaller grains. For ECAP-C at the lowest temperature of $423 \mathrm{~K}$, the grains retained a higher degree of grain shape anisotropy, with the long axes oriented in the direction of shearing during ECAP-C, $49.8^{\circ}$ away
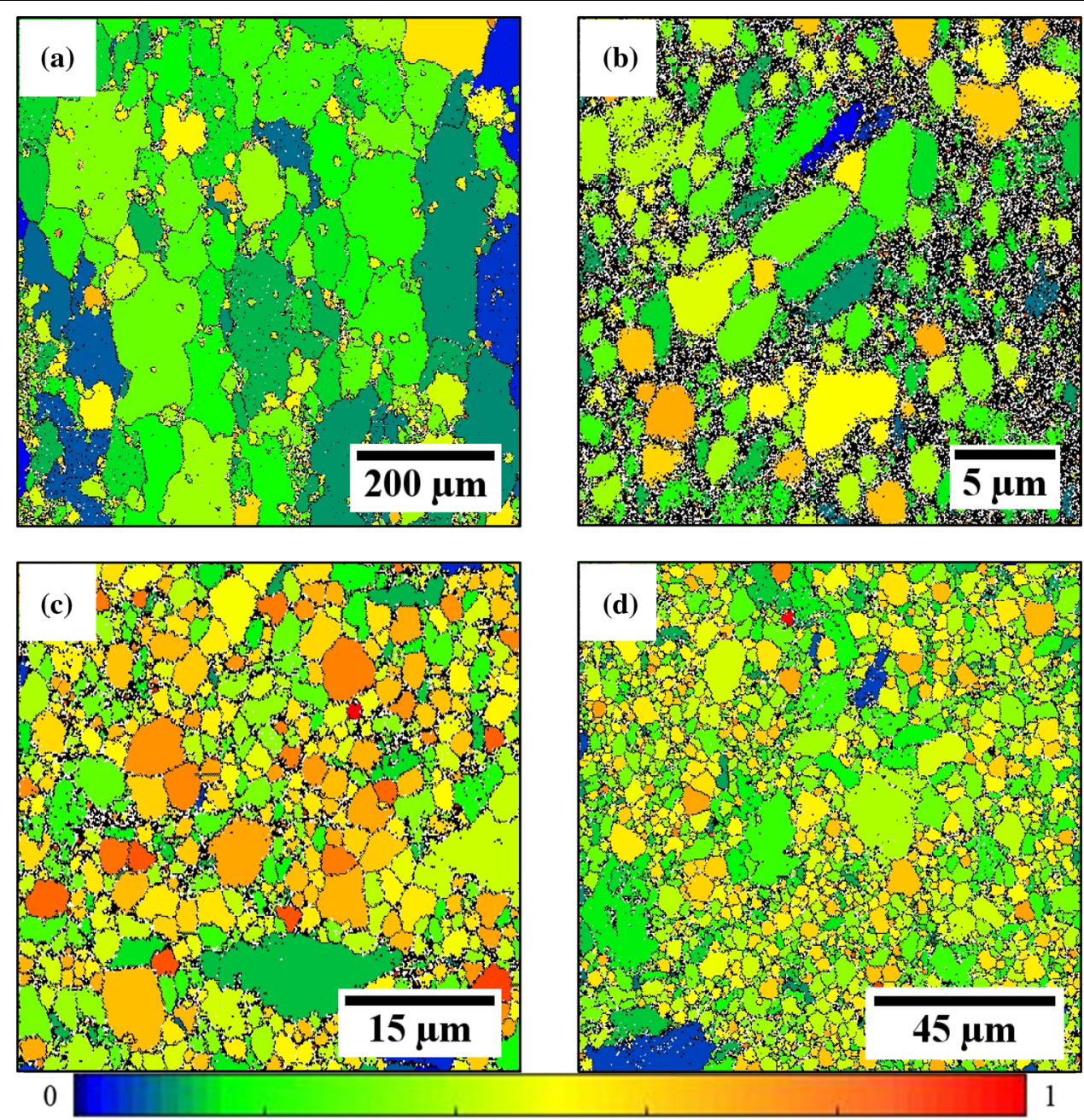

Fig. 2. Longitudinal section aspect ratio maps for (a) AR and two-pass ECAP-C samples processed at a feed rate of $8 \mathrm{~mm} / \mathrm{s}$ via route $A$ at (b) $423 \mathrm{~K}$, (c) $473 \mathrm{~K}$, and (d) $523 \mathrm{~K}$. 


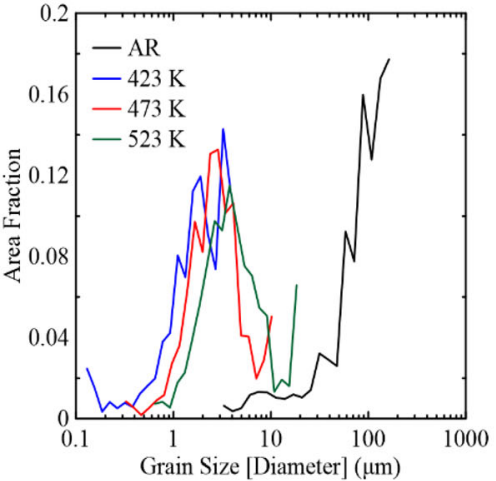

(a)

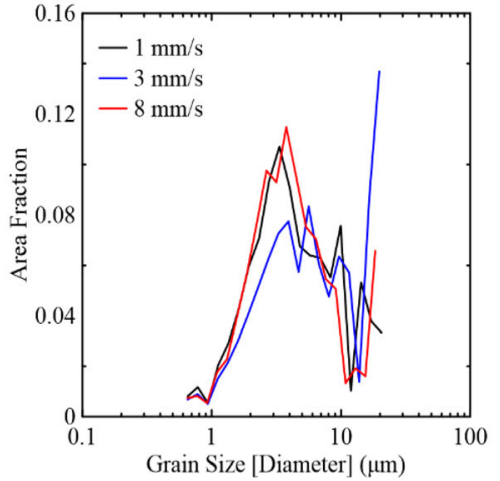

(b)

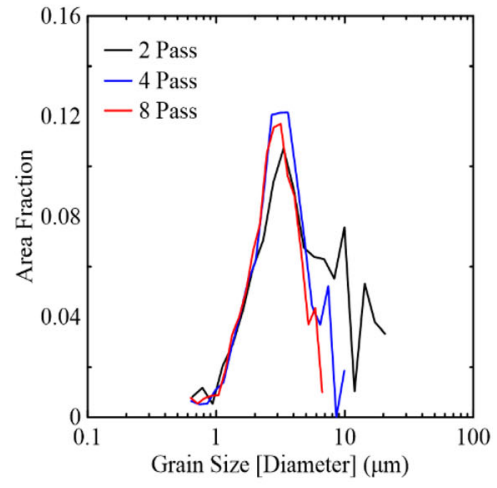

(c)

Fig. 3. Area fraction versus grain size (log scale) showing dependence of grain size distribution (a) on temperature for two passes at $8 \mathrm{~mm} / \mathrm{s}$, (b) feed rate for two passes at $523 \mathrm{~K}$, and (c) number of passes at $1 \mathrm{~mm} / \mathrm{s}$ at $523 \mathrm{~K}$.

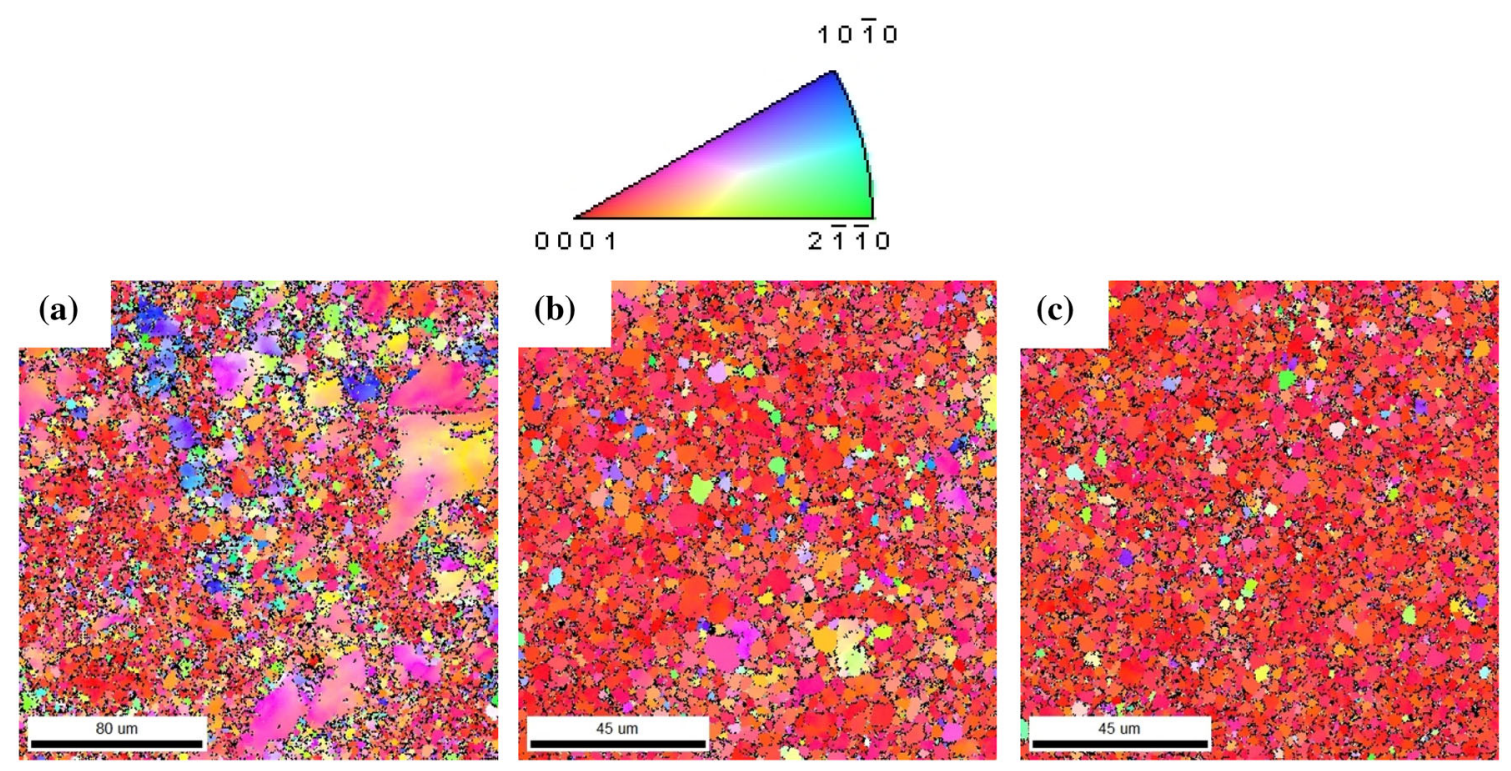

Fig. 4. Normal direction (ND) IPF maps for route A ECAP-C samples at $523 \mathrm{~K}$ and $1 \mathrm{~mm} / \mathrm{s}$ for (a) two passes, (b) four passes, and (c) eight passes
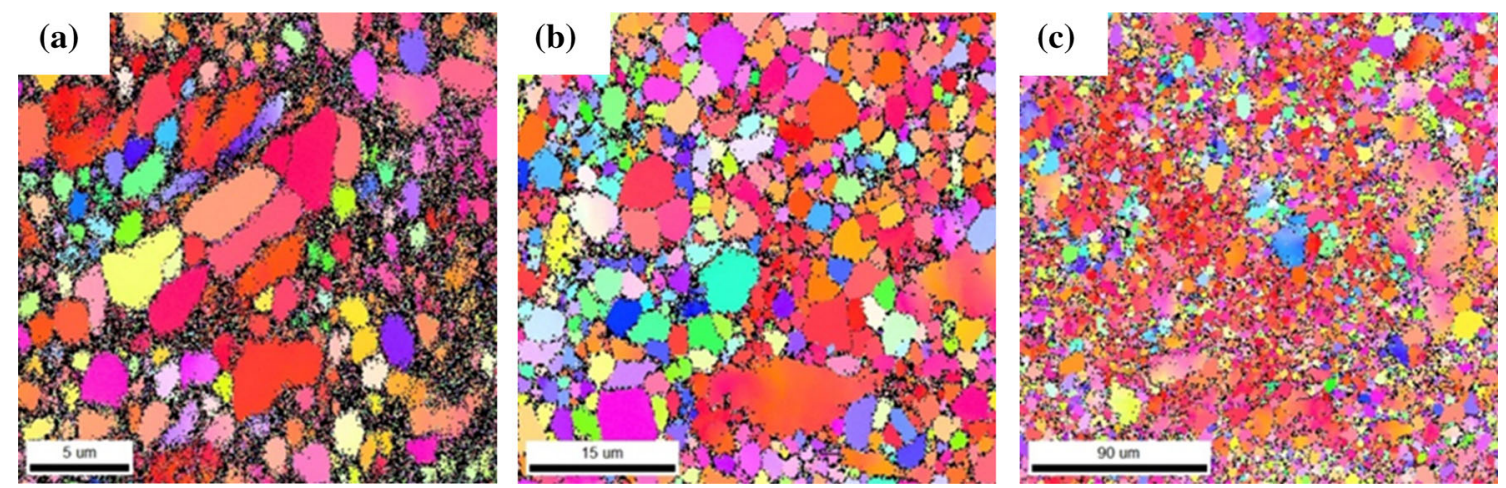

Fig. 5. Normal direction (ND) IPF maps for two-pass route A ECAP-C samples at $8 \mathrm{~mm} / \mathrm{s}$ and (a) $423 \mathrm{~K}$, (b) $473 \mathrm{~K}$, and (c) $523 \mathrm{KFig.} 6 \mathrm{Tensile}$ stress-strain curves showing the effects of (a) ECAP-C temperature, (b) processing rate, and (c) number of passes on the mechanical properties. 
from the extrusion axis. ECAP-C at $473 \mathrm{~K}$ resulted in a larger fraction of more equiaxed grains, as seen in Fig. 2c. The average aspect ratios of the processed samples were $0.42,0.45$, and 0.49 at $423 \mathrm{~K}$, $473 \mathrm{~K}$, and $523 \mathrm{~K}$, respectively. This trend toward higher aspect ratios for higher temperatures is consistent for all ECAP-C feed rates.

Even for two passes of ECAP-C by route A, a preferred crystallographic texture emerged, as shown by the normal direction (ND) inverse pole figure maps (IPF) in Fig. 4. The basal planes $\{0001\}$ tend to align their normals perpendicular to the normal direction of the ECAP-C billets and, on average, oriented between $67.2^{\circ}$ and $84^{\circ}$ away from the extrusion axis. The same preferred crystallographic orientation distribution as shown in Fig. 4 formed at all feed rates and temperatures. For all combinations of temperature and feed rate studied, increasing the number of passes tended to slightly increase the average degree of rotation of basal planes away from the extrusion axis.

The effects of temperature and feed rate on grain size distributions are shown in Fig. 3. The grain size distributions shift to larger sizes with increasing temperature, as seen in Fig. 3a. Notably, the area fractions of grains $<2 \mu \mathrm{m}$ increase with decreasing ECAP-C temperature. The bimodal characteristic was evident at all temperatures for two-pass samples, as indicated by the upturn of area fraction curves at the larger grain sizes. The biomodality is also shown in the IPF maps in Fig. 5. The effect of the feed rate was measured at all temperatures and found to have only a small effect on the grain size distribution. The grain size distributions in Fig. 3b for ECAP-C at $523 \mathrm{~K}$ show nearly identical grain size distributions for ECAP-C at $1 \mathrm{~mm} / \mathrm{s}$ and $8 \mathrm{~mm} /$ s. Interestingly, the grain size distribution for ECAP-C at $3 \mathrm{~mm} / \mathrm{s}$ shows pronounced bimodality and therefore a reduced fraction of grains near the mean grain size for the peak at smaller grain sizes. The lower fraction of grain sizes near $3 \mu \mathrm{m}$ appears because of the large area fraction of a few multimicron grains in the area scanned by EBSD. Nevertheless, a full multi-variable analysis of variance (ANOVA) of all samples and all parameters showed no statistically significant influence of the feed rate on grain size. Finally, Figs. 4 and 3c show that the fraction of remnant larger-sized grains diminishes with increasing numbers of passes.

\section{RESULTS: TENSILE PROPERTIES}

Tensile testing results for samples processed by route A are shown in Fig. 6. Figure 6a shows that the processing temperature has a direct effect on the yield strength $\left(\sigma_{\mathrm{y}}\right)$, ultimate tensile strength (UTS), and percent elongation to failure. As the processing temperature increases, the UTS and $\sigma_{\mathrm{y}}$ decrease while the percent elongation to failure increases. Figure $6 \mathrm{~b}$ shows essentially no effect of feed rate on mechanical properties, at least over the range of rates studied. The number of passes has varying effects, as shown in Fig. 6c, depending on the processing temperature. At $423 \mathrm{~K}$, the elongation to failure increases with the number of passes, whereas, at $523 \mathrm{~K}$, the elongation to failure varied only slightly between the two- and four-pass samples, but decreased after eight passes. Table I summarizes the UTS, $\sigma_{\mathrm{y}}$, and percent elongation for the two-, four-, and eight-pass samples, corresponding to effective strains of $1.34,2.68$, and 5.36, respectively.

\section{COIL-TO-COIL ECAP-C}

The microstructures and mechanical properties achieved via isothermal ECAP-C were sufficiently encouraging to motivate exploration of coil-to-coil ECAP-C processing. Coil-to-coil processing offers efficiency for scaling commercial ECAP-C and exploits the intrinsic curvature that exists in ECAP-C billets. Rotations of the billets between passes are straightforward for ECAP of single rods so long as the billets remain straight. However, this is rarely the case. If a billet with a length of $3 \mathrm{~m}$ has moderate curvature, interpass rotations of 90 degrees and billet pre-heating in furnaces can be impractical because of the difficulty of handling. For long billets with slight curvature, it is advantageous to coil the billets, especially in view of the need for interpass billet rotations. Economical production of UFG $\mathrm{Mg}$ favors the implementation of coiling of billets to maximize throughput and minimize yield loss.

To explore continuous ECAP-C, a prototype coiling system was designed for both room temperature operation and mounting within a $1.3 \mathrm{~m} \times 1.3$ $\mathrm{m} \times 1.3 \mathrm{~m}$ furnace hot zone, as shown in Fig. 7 . Both the feed-coiler and take-up coiler were designed so they could be re-oriented by $90^{\circ}$ to allow route $\mathrm{B}$ rotations. To implement route A processing, the head of a coiled billet must be accessible for re-feeding into ECAP-C tooling for each subsequent pass. This constraint prevented coiling multiple layers onto a spindle, thereby limiting the maximum coiled billet length to between $120 \mathrm{~m}$ (for $12 \mathrm{~mm}$ diameter billets) and $180 \mathrm{~m}$ (for $8 \mathrm{~mm}$ diameter billets).

The coiling system operation was piloted at room temperature using 12-mm-diameter rods to demonstrate the operability of the system. The system was tested using billets up to $30 \mathrm{~m}$ in length. It functioned as designed and without any difficulties.

\section{DISCUSSION}

Focusing first on the mechanical properties, we see that temperature is the most critical ECAP-C processing parameter for achieving the highest strength in AZ31. This is partly because the relative amounts of deformation by the slip, twinning, and grain boundary sliding mechanisms depend on 

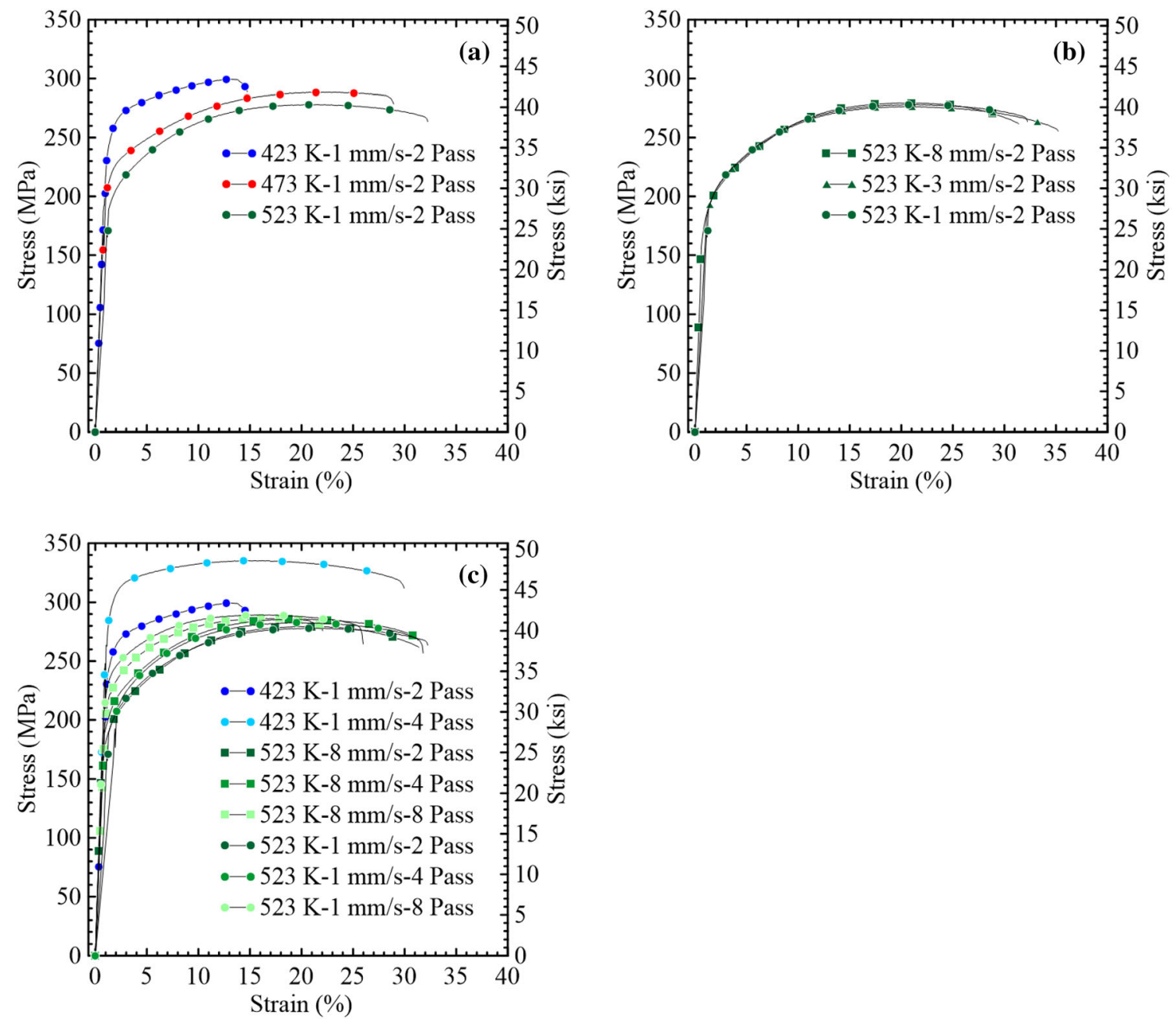

Fig. 6. Tensile stress strain curves showing the effects of (a) ECAP-C temperature (b) processing rate, and (c) number of passes on the mechanical properties.

Table I. Yield stress, UTS, and \% elongation to failure measured in samples processed given the number of passes and other ECAP-C parameters

\begin{tabular}{|c|c|c|c|c|}
\hline \multirow[b]{2}{*}{ Material property } & \multirow[b]{2}{*}{ Feed rate $(\mathrm{mm} / \mathrm{s})$} & \multicolumn{3}{|c|}{ Temperature (K) } \\
\hline & & 423 & 473 & 523 \\
\hline \multirow{3}{*}{$\sigma_{\mathrm{y}}(\mathrm{MPa})$} & 1 & 235.0 & 201.7 & 197.7 \\
\hline & 3 & 240.5 & 213.5 & 185.5 \\
\hline & 8 & - & 201.3 & 187.3 \\
\hline \multirow[t]{3}{*}{ UTS (MPa) } & 1 & 299.7 & 288.9 & 279.9 \\
\hline & 3 & 295.1 & 287.6 & 277.3 \\
\hline & 8 & - & 280.5 & 279.7 \\
\hline \multirow[t]{3}{*}{$\%$ elongation to failure (\%) } & 1 & 14.7 & 28.1 & 33.5 \\
\hline & 3 & 11.0 & 25.1 & 34.5 \\
\hline & 8 & - & 34.2 & 31.5 \\
\hline
\end{tabular}

temperature. A study completed by Kim et al. associated the formation of shear bands at $473 \mathrm{~K}$ with an increase of twinning present at higher temperatures in alpha titanium, which, like $\mathrm{Mg}$, has a hexagonal close-packed crystal structure. ${ }^{30}$ The largest amount of twinning in $\mathrm{Ti}$ was observed in samples processed at $673 \mathrm{~K}$. Likewise, for materials with low ductility, such as magnesium, high temperatures are needed to ensure there are enough activated slip systems to prevent fracture. Agnew 


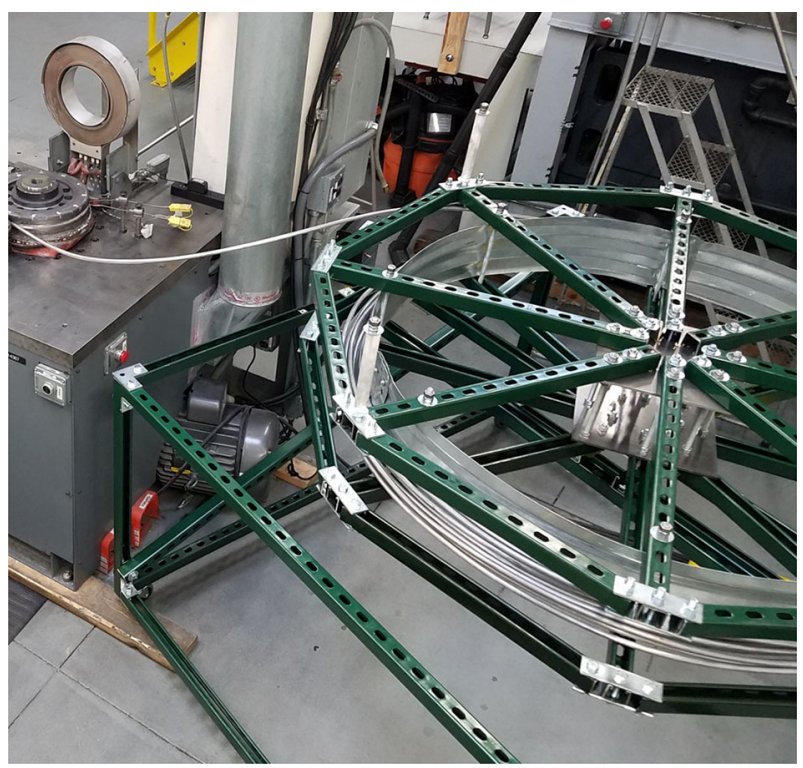

Fig. 7. Prototype coil-to-coil system in operation with the $\gamma$ ECAP-C machine at the Nanostructured Metals Manufacturing Testbed.

et al. demonstrated that different $\mathrm{Mg}$ alloys failed during ECAP processing with a die angle of $90^{\circ}$ because of large shear cracks at temperatures $<448$ $\mathrm{K}^{5,13,32}$ It is also noted that there is limited grain refinement in many $\mathrm{Mg}$ alloys at temperatures $>573 \mathrm{~K}^{5}$ Depending on the alloy system, the processing temperature can affect the grain size evolution, grain boundary structure, deformation mechanism, or a combination thereof. At room temperature, the reported ratios of the CRSS between the basal $\langle a\rangle$ :prismatic $\langle a\rangle:$ pyramidal $\langle c+a\rangle$ :tensile twin modes in $\mathrm{Mg}$ are 1:(3.2-15):(522.5):(1.2-3). ${ }^{31-34}$ The twin mode and basal deformation are insensitive to temperature, whereas the prismatic and pyramidal mechanisms are more temperature-dependent. As the temperature increases, the CRSSs for the prismatic and pyramidal modes are reduced allowing a larger number of activated slip systems. ${ }^{35}$ The relative amounts of slip on different slip systems plus the amounts of twinning will also influence which textures form, which in turn influences the mechanical properties. The amount of grain refinement caused by ECAP-C is also sensitive to temperature since the balance among dislocation storage, recovery, and dynamic recrystallization is temperature-dependent. Our tensile tests showed the highest strength achieved by isothermal processing was $333.5 \mathrm{MPa}$ after four ECAP-C passes at the lowest temperature studied, $423 \mathrm{~K}$, and a feed rate of $1 \mathrm{~mm} / \mathrm{s}$. While this processing condition did not produce the smallest grain size, it appears to have imparted a high dislocation density, as shown by the low image quality in the EBSD IPF maps shown in Fig. 4.

For all conditions studied, the elongation to failure after ECAP-C was $>11 \%$ and as high as $34.5 \%$. Figure $6 \mathrm{c}$ shows that the highest measured strength was obtained after four ECAP-C passes at $423 \mathrm{~K}$, yet maintaining a ductility of $28 \%$. For just two passes of ECAP-C, the classic tradeoff between strength and ductility persists, as seen in Fig. 6a, but with increasing amounts of ECAP-C, it is possible to increase the strength and ductility, as shown in Fig. 6c. One plausible explanation of the high ductility after four passes can be inferred from the grain size distribution, as shown in Fig. 4 for ECAP-C at a feed rate of $1 \mathrm{~mm} / \mathrm{s}$ and a temperature of $423 \mathrm{~K}$. While the image quality is relatively poor, there is still clear evidence of the presence of large and small grains together. We believe that the presence of large grains contributes to ductility, while the surrounding small grains increase the strength. The association of combined high strength and ductility with bimodal grain size distributions after ECAP has been reported by Fintová and Kunz. ${ }^{36}$

The implementation of coil-to-coil ECAP-C addresses the need for continuous large-scale production if $\mathrm{Mg}$ alloys are to become viable for absorbable implant applications. Prospective initial applications for absorbable $\mathrm{Mg}$ include coronary stents and trauma fixation, such as bone screws. Both products are manufactured from coiled small diameter rod. Thus, the ability to coil ECAP-Cprocessed bars and rods addresses a critical milestone for producing a suitable product form with acceptable material properties. Being able to process long continuous lengths of $\mathrm{Mg}$ also enables the possibility of intentionally operating ECAP-C at high rates without preheating, relying solely on achieving steady-state adiabatic heating to provide the necessary thermal energy and temperatures $>$ $423 \mathrm{~K}$ during processing. While this possibility was not explored in this work, it merits additional research, including computational modeling to estimate the rates needed to establish a steady-state deformation in the shear zone near the desired temperature of $423 \mathrm{~K}$. It is also important to investigate additional $\mathrm{Mg}$ alloys, particularly with alloy chemistries optimized for better biocompatibility and slower degradation by in vivo corrosion.

\section{CONCLUSION}

This research developed the parameters for isothermally processing AZ31 by ECAP-C, a promising method for large-scale manufacturing of UFG materials via SPD. With no additional backpressure, the extruded AZ31 rod with coarse grains ( $>$ $100 \mu \mathrm{m}$ ) was isothermally processed by ECAP-C at temperatures between $423 \mathrm{~K}$ and $523 \mathrm{~K}$ and processing feed rates between $1 \mathrm{~mm} / \mathrm{s}$ up to $8 \mathrm{~mm} / \mathrm{s}$. The maximum ultimate tensile strength of 333.5 $\mathrm{MPa}$ was achieved via route A ECAP-C, providing an elongation of $28 \%$. Such properties are suitable for producing bioabsorbable stents and trauma fixation. The corresponding average grain size was approximately $1 \mu \mathrm{m}$. However, the combination of 
reasonably high strength and high ductility was attributed to the presence of a bimodal grain size distribution, including multi-micron- and sub-micron-sized grains.

A system for coil-to-coil operation was developed and tested, further demonstrating the viability of continuous ECAP providing $\mathrm{Mg}$ suitable for medical applications. Future studies will examine the possibility of achieving steady-state heating in long billets using the prototype coil-to-coil system. ECAP-C will also be evaluated for additional $\mathrm{Mg}$ alloy systems.

\section{ACKNOWLEDGEMENTS}

Authors CFD and TCL are grateful for the skill and effort of Joel Davis, a member of the Colorado School of Mines' Transdisciplinary Nanostructured Material Research Team (TNMRT), for designing and constructing the prototype coiling system for use with ECAP-C.

\section{CONFLICT OF INTEREST}

The authors declare they have no conflict of interest.

\section{REFERENCES}

1. O. Iida, M. Uematsu, Y. Soga, K. Hirano, K. Suzuki, H. Yokoi, T. Muramatsu, N. Inoue, S. Nanto, and S. Nagata, Catheter. Cardiovasc. Interv. 78, 611 (2011).

2. H.S. Brar, B.G. Keselowsky, M. Sarntinoranont, and M.V. Manuel, JOM 63, 100 (2011).

3. S.X. Ding, W.T. Lee, C.P. Chang, L.W. Chang, and P.W. Kao, Scr. Mater. 59, 1006 (2008).

4. Y. Chen, Z. Xu, C. Smith, and J. Sankar, Acta Biomater. 10, 4561 (2014).

5. S.R. Agnew, P. Mehrotra, T.M. Lillo, G.M. Stoica, and P.K Liaw, Acta Mater. 53, 3135 (2005).

6. R.B. Figueiredo and T.G. Langdon, J. Mater. Sci. 45, 4827 (2010).

7. E. Mostaeda, M. Khashempourb, A. Fabrizic, D. Dellasegad, M. Bestettib, F. Bonolloc, and M. Vedania, J. Mech. Behav. Biomed. Mater. 37, 307 (2014).

8. K. Matsubara, Y. Miyahara, Z. Horita, and T.G. Langdon, Acta Mater. 51, 3073 (2003).

9. S. Seipp, M.F.-X. Wagner, K. Hockauf, I. Schneider, L.W. Meyer, and M. Hockauf, Int. J. Plast. 35, 155 (2012).

10. Y. Miyahara, Z. Horita, and T.G. Langdon, Mater. Sci. Eng. A 420, 240 (2006).
11. J. Suh, J. Victoria-Hernández, D. Letzig, R. Golle, and W. Volk, Mater. Sci. Eng. A 669, 159 (2016).

12. R.B. Figueiredo and T.G. Langdon, Mater. Sci. Eng. A 501, 105 (2009).

13. S.R. Agnew, J.A. Horton, T.M. Lillo, and D.W. Brown, Scr. Mater. 50, 377 (2004).

14. M. Mabuchi, K. Ameyama, H. Iwasaki, and K. Higashi, Acta Mater. 47, 2047 (1999).

15. W.J. Kim, C.W. An, Y.S. Kim, and S.I. Hong, Scr. Mater. 47, $39(2002)$

16. W.J. Kim, S.I. Hong, Y.S. Kim, S.H. Min, H.T. Jeong, and J.D. Lee, Acta Mater. 51, 3293 (2003).

17. A. Muralidhar, S. Narendranath, and H. Shivananda Nayaka, J. Magn. Alloys 1, 336 (2013).

18. K. Xia, J.T. Wang, X. Wu, G. Chen, and M. Gurvan, Mater. Sci. Eng. A 410, 324 (2005).

19. A. Ma, J. Jiang, N. Saito, I. Shigematsu, Y. Yuan, D. Yang, and Y. Nishida, Mater. Sci. Eng. A 513, 122 (2009).

20. L. Jin, D. Lin, D. Mao, X. Zeng, and W. Ding, Mater. Lett. 59, 2267 (2005).

21. R.B. Figueiredo and T.G. Langdon, J. Mater. Sci. 43, 7366 (2008).

22. H.K. Kim, Y.I. Lee, and C.S. Chung, Scr. Mater. 52, 473 (2005).

23. H. Wang, Y. Estrin, and Z. Zúberová, Mater. Lett. 62, 2476 (2008).

24. G.J. Raab, R.Z. Valiev, T.C. Lowe, and Y.T. Zhu, Mater. Sci. Eng. A 382, 30 (2004).

25. R. Lapovok, L.S. Tóth, A. Molinari, and Y. Estrin, J. Mech. Phys. Solids 57, 122 (2009).

26. F. Kang, J.T. Wang, and Y. Peng, Mater. Sci. Eng. A 487, 68 (2008).

27. R. Lapovok, Y. Estrin, M.V. Popov, and T.G. Langdon, Adv. Eng. Mater. 10, 429 (2008).

28. R. Lapovok, R. Cottam, P.F. Thomson, and Y. Estrin, J. Mater. Res. 20, 1375 (2005).

29. R. Lapovok, Y. Estrin, M.V. Popov, S. Rundell, and T. Williams, J. Mater. Sci. 43, 7372 (2008)

30. I. Kim, J. Kim, D.H. Shin, C.S. Lee, and S.K. Hwang, Mater. Sci. Eng. A 342, 302 (2003).

31. P. Cizek and M.R. Barnett, Scr. Mater. 59, 959 (2008).

32. F. Kabirian, A.S. Khan, and T. Gnäupel-Herlod, Int. J. Plast. 68, 1 (2015).

33. A. Jain and S.R. Agnew, Mater. Sci. Eng. A 462, 29 (2007).

34. S.R. Agnew, C.N. Tomé, D.W. Brown, T.M. Holden, and S.C. Vogel, Scr. Mater. 48, 1003 (2003).

35. M. Ardeljan, I.J. Beyerlein, B.A. McWilliams, and M. Knezevic, Int. J. Plast. 83, 90 (2016).

36. S. Fintová and L. Kunz, J. Mech. Behavior Biomed. Mater. 42,219 (2014)

Publisher's Note Springer Nature remains neutral with regard to jurisdictional claims in published maps and institutional affiliations. 